\title{
The Role of Motivation and Controversial Conceptual Material in Foreign Language Classrooms
}

\author{
Antonio R. Iaccarino \\ Marlboro College Graduate, USA \\ Email: ari@marlboro.edu
}

\begin{abstract}
Spanish classrooms in the U.S. rarely teach students about the tumultuous relationship with natives of the target language, and this lack of material can leave the learner without certain linguistic knowledge. The novelty of exploring controversial relationships in the target language has the possibility of challenging students' conceptions of the world which can open up different channels for motivation in the classroom, and ultimately, language learning.
\end{abstract}

Index Terms-Spanish, motivation, conceptual material, foreign language, ACTFL, Piaget, goal orientation, interest, self-efficacy, control factors

Many students are taught a foreign language through static (or "matter-of-fact") themes such as daily activities, cooking recipes, or holidays. Rarely are U.S. second language learners exposed to stories or histories that reveal the more complex and potentially controversial aspects of their own country and its relationship to target-language nations. Instead, many students are taught in a curriculum of nationalism and continue to assimilate simple contextual views, but in a different language. ${ }^{1}$ By combining second language learning ${ }^{2}$ with an exposure to histories and stories that challenge previous static beliefs in the context of controversial conceptual change, second language learners will be potentially motivated to learn the new language in order to either support their original point of view or, alternatively, to accommodate to the newly presented material.

Much of the material in foreign language classrooms focuses on subjects such as daily interactions, food, cultural norms, and small snippets of history, but rarely emphasizes controversial contemporary and historical relationships between the native language (L1) and the target language (TL) population. Although the material that is being taught now (daily activities, etc.) is important for day-to-day interaction, to not learn about the complex past-present relations between the L1 and TL population is similar to a Christian U.S. language student learning Arabic without any idea of the Prophet Muhammad. Raising controversial topics in the foreign language classroom has the possibility of not only enriching students' conceptual understanding of the TL country(ies) and their own, but of also capturing their attention. The material would allow for more intake and an increase in motivation to use the TL to produce comprehensible output. Language classes should not just use controversial conceptual material as the sole part of the curriculum, but should include it, at some point in time, as an integral chapter of the L2 learner's education.

The relationship between L1 and TL learning in controversial conceptual material is varied amongst languages. Not all L1s and TLs will have a complex and controversial history. For example: If the L1 is German and the TL is Punjabi; if the L1 is Swahili and the TL is Spanish; if the L1 is Tagalog and the TL is Urdu. In these language relationships there lacks a strong historical/contemporary domination or controversial interaction, which could be compared to the following; if the L1 is English and the TL is Spanish, is the L1 is French and the TL is Vietnamese, if the L1 is Korean and the TL is Japanese, if the L1 is Mandarin and the TL is Tibetan. In the latter relationships there is a controversial past and present between nations that speak the specific languages. It is not just the hot relationship between countries that would motivate students' language use, but the direct influences in how their country interacts and is perceived in the world because of these controversial interactions. A student's social position in relation to the TL will affect language learning. If the student comes from a country that has been dominated by the TL, the student might develop increased negative emotions towards the TL and not be motivated to learn. This paper will not discuss student motivation from countries or subgroups within those nations that have been dominated by the TL. Instead the focus will concern student motivation from countries that have dominated or controversially affected the TL population, specifically English learners of Spanish in the United States.

Many U.S. students are unaware of negative perspectives that arise from the imperialistic history of the United States and its supposed role in suppressing democracy and human rights throughout the world; but more specifically, many

\footnotetext{
${ }^{1}$ This paper is not an attempt to lay out in detail how language is taught, but draws on the author's personal learning and observation of Spanish in high schools.

${ }^{2}$ Throughout the article I will refer to second language learning as the general acquisition of a new language, which is not limited to just a second language, but possibly a third or more. The same reference applies for second language learners, who already might be bilingual.
} 
U.S. students are unaware of this relationship vis-à-vis Central and South America. Consequently, United States English speaking students are learning Spanish without any idea of the politics that shape human relations between the two regions. Students have the potential to benefit from discussing broad historical and contemporary interaction between the L2 learner's country and the TL nation because of the access to increased contextual knowledge.

Foreign language learning is different from many other subjects in school because of the interdisciplinary mix of literature, art, history and music that allow insights into a collective psychology. In chapter 3, "Motivation, Anxiety and Emotion in Second Language Acquisition," of the book Individual Differences and Instructed Language Learning, Peter MacIntyre reiterates the psychological correlation by saying "It is the emphasis on culture, psychological identification with a specific cultural group, and changes in identity that most clearly distinguish language learning from other subjects studied in school" (italics added)(Macintyre n.d., p. 54). If L2s are only being exposed to limited pieces of information, they will cease to acquire a fuller picture of the target-language community, thus reducing conceptual expansion. In addition to knowing syntax, grammar and vocabulary, language has the potential to be dynamic and exhibit varied implicit meanings, as certain words are derived from historical events and are utilized differently in communication mediums.

An example of such a word in Spanish that has its origins in the recent history of U.S. foreign policy in Latin America which might not be obvious to a L2 learner based off simple translation is the word "To disappear" or desaparecer. The verb was newly defined during the twentieth century military dictatorships in Latin America as "disappear" took on a political meaning "to disappear someone" (desaparecer), describing those considered threats to the State who were kidnapped, tortured, and disappeared by their own national security forces ("The Disappeared”, n.d.). The Federación Latinoamericana de Asociaciones de Familiares de Detenidos-Desaparecidos (FEDEFAM, n.d.), a nonprofit humanitarian organization formed by relatives of the "disappeared," define the process of disappearing somebody as a forced disappearance:

A forced disappearance consists of a kidnapping, carried out by agents of the State or organized groups of private individuals who act with State support or tolerance, in which the victim "disappears". Authorities neither accept responsibility for the deed, nor account for the whereabouts of the victim. Petitions of habeas corpus or "amparo"- legal mechanisms designated to safeguard the liberty and integrity of citizens-are ineffective, and the kidnappers remain anonymous (FEDEFAM, n.d.).

Once a L2 learner of Spanish has been exposed to the above, their conceptual idea of the words "to disappear someone" (desaparecer) and "the disappeared" (los desaparecidos) acquires a historical and political position in their Spanish language learning. Additionally, the support of the L2 learner's home nation (the United States) in advocating military dictatorships may challenge previous student conceptions about the U.S. as a bastion of a democratic society. In doing so, meaningful conversation, questions, or criticisms may arise and the motivation to use the target language to convey thoughts and emotion will increase. When L2 learners are taught that learning a new language is not just a cold process to gain skills in a target language, but a powerful and sometimes controversial journey that allows them to discover their world through mediums of art, literature, music, history, and meaningful dialogue, their motivation to absorb and use the target language may increase in order to explain and affirm their conceptions.

While introducing controversial conceptual material opens new possibilities in motivating language learners, it can only be successful if certain preconditions have been satisfied. First, proficiency levels have an impact on how and to whom controversial conceptual material is presented in the L2 classroom. According to ACTFL's (American Council on the Teaching of Foreign Languages) sample progress indicator, $12^{\text {th }}$ graders should be able to:

- Exchange, support, and discuss their opinions and individual perspectives with peers and/or speakers of the target language on a variety of topics dealing with contemporary and historical issues.

- Demonstrate an increasing understanding of the cultural nuances of meaning in written and spoken language as expressed by speakers and writers of the target language in formal and informal settings.

- Prepare a research based analysis of a current event from the perspective of both the U.S. and target cultures (ACTFL, 2000).

The above indicators are the ideal results of a successful working curriculum that includes controversial conceptual material. One could assume that, based on a well delivered language education, students in $10^{\text {th }}$ or $11^{\text {th }}$ grade have the CALP (Cognitive Academic Language Proficiency) to begin utilizing controversial conceptual material (Cummins, n.d.). The second condition that must be met is the establishment of a functional pedagogy. The presentation and dialogue concerning controversial conceptual material will be most effective within the Communicative Language Teaching method (CLT). CLT is based on the idea that "successful language learning involves not only a knowledge of the structures and forms of a language, but also the functions and purposes that a language serves in different communicative settings" (Lightbrown, 2006, p. 196). Essentially communication of meaning is emphasized rather than pure grammatical practice. Within the CLT approach, there is "content-based instruction." Content-based instruction classes are foreign language programs in which lessons are formed around subject matter rather than "language points" and again emphasize meaning over form (Ibid, 197). Lightbrown and Spada emphasize the importance of content-based instruction:

It [content-based instruction] creates a genuine need to communicate, motivating students to acquire language in order to understand the content. For older students, there is the advantage of content that is cognitively challenging and 
interesting in a way that is often missing in foreign language instruction, especially where lessons are designed around particular grammatical forms (Ibid, 159).

When students are given contextual information and the opportunity to communicate, conversation no longer becomes predictable, but instead inspires the L2 speakers to express their personal values, use a logical form to defend their opinions, and draw on cognitive resources to form their ideas into the TL. After explaining controversial conceptual material as a beneficial component of language learning, one can see how it can increase motivation using the conceptual change model.

The conceptual change model was authored by Posner and colleagues (Posner, Strike, Hewson, Gertzog, 1982), and based on Jean Piaget's theories of assimilation and accommodation. Piaget stated that assimilation involved applying a new object into an old schema (Boeree, n.d.). For example, many high school aged students are aware that certain produce is imported into the U.S. In a lesson about commerce between the U.S. and other Spanish speaking countries, a student might learn about the origin of certain produce, such as the large amount of bananas imported by companies like the banana brand Chiquita from Colombia. One more semantic fact is assimilated into an old schema of commerce, maintaining the system of a world market. The assimilation of this information can be modeled in the following image (Atherton, 2005):

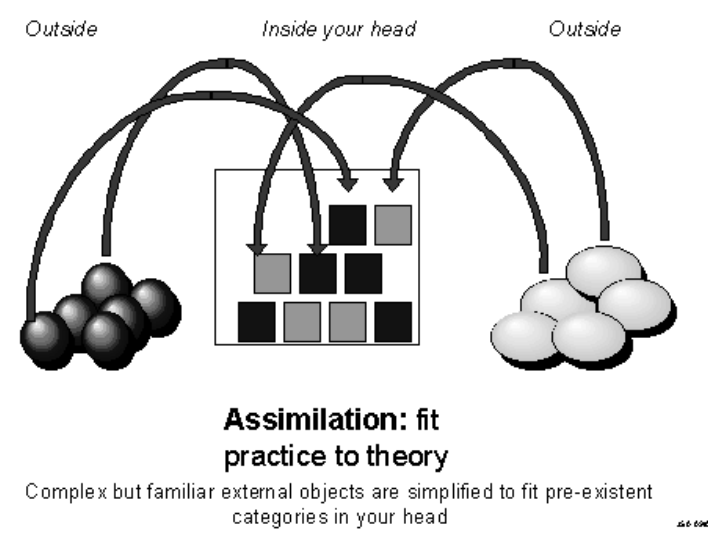

The incoming information to the L2 learner is non-challenging, and conceptually the same as before, just with another fact. It would be hard for a language teacher to engage in any stimulating or motivation conversation with students about knowledge that is already known, just expanded. Accommodation, on the other hand, is the process of adapting an old schema to a new object (Boeree, n.d.). Instead of the L2 learner's previous lesson based on assimilative information, the L2 student now has a lesson that includes controversial material. The student is now exposed to material that not only mentions Chiquita as a principal importer of bananas from Colombia, but also its complex role by indirectly supporting murder and massacres among the Colombian civilian population (Kroft, 2008). The fact that this U.S. based company preferred to pay an unofficial "tax" to paramilitaries in order to protect its economic interests, which in turn funded the armed group's exploits, has the propensity to challenge a student's conception about the state of the world market. If a student already knew about the above material, then he would assimilate this new object (Chiquita scandal) to his already existing conceptual idea of Latin American-U.S. economic relations. If the student on the other hand was not aware of any events as such, and it conflicted with his strong foundations in the current system, this would cause a state of disequilibrium. If the student finds that the old schema (the original world market as totally beneficial) needs to adapt to the new object (Chiquita scandal), this will cause accommodation. A model of accommodation is shown below (Atherton, 2005):


external objects 
The incoming information to the student is different and conceptually challenging, in that it tests the functionality and overall performance of production, distribution, and profit in the current world market. Controversial conceptual material will be easier for a teacher to implement in a class discussion that challenges the way students buy and consume on a daily basis, affecting their connection of the target language countries. The above example is not to debate whether the world market is "good" or "bad," but to show how a discussion of this controversial subject has the propensity to increase L2 learners' motivation to use the TL because of its meaningful content. L2 learners will draw on their cognitive TL resources to defend the previous conception, support the accommodation of the bananas-for-blood conception, or debate something in-between.

In Posner's article "Accommodation of a Scientific Conception: Toward a Theory of Conceptual Change" (1982), he writes of assimilation and accommodation as the acquisition of knowledge based on comprehensibility and reason:

Our central commitment in this study is that learning is a rational activity. That is, learning is fundamentally coming to comprehend and accept ideas because they are seen as intelligible and rational... We believe it follows that learning, like inquiry, is best viewed as a process of conceptual change. The basic question concerns how students' conceptions change under the impact of new ideas and new evidence (212).

Posner states that four conditions must be met for accommodation to occur in students. The first is that there must be dissatisfaction with existing conceptions, a collection of anomalies and "lost faith" in the ability of a current conception to solve problems (214). For example, the L2 learner is exposed to controversial conceptual material that challenges his perception of the current world market as the most beneficial system of production and distribution for everybody, and after a while the previous conception fails to answer his questions about fairness and opportunities for the disadvantaged in the these societies (such as the Chiquita scandal). Next, the new material has to be intelligible, or understood in order to see how it could affect the future (Ibid). For example, the L2 understands alternative ideas for production and distribution of goods in Latin America, such as fair-trade, green technology, increased allocation of profit to the general public etc. Third, the new conception must be plausible, in that it must have the capacity to solve previous problems the original concept was unable to fix (Ibid). For example, an L2 student learns about banana farmer cooperatives in Latin American countries that benefit traditional agrarian families otherwise excluded or disadvantaged by large agricultural companies. The L2 learner is also shown the increased presence of fair-trade bananas sold in U.S. stores. The alternative is now plausible in the mind of the student. Fourth and last, the new concept should be fruitful (no pun intended), meaning it has the potential to open up new areas of inquiry (Ibid). For example, the L2 now believes there is a possibility that the benefits of fair trade could extend to other products in the market, such as oranges, coffee beans, and other staples. The L2 learner has experienced an accommodation change, in that he has been exposed to controversial conceptual material that "complexified" his previous perceptions, prompting him to consider the new information in a logical process.

One can not assume that conceptual change or motivation will occur just because there is a rational and logical problem occurring in a language learner's brain. Adolescent students in the classroom rarely have the same goals and states of being as a professional researcher. Pintrich, Marx, and Boyle (1993) critiqued Posner's notion that conceptual change will occur simply because of a logical crisis:

That is, it suggests that learners behave very much like scientists in that, when they become dissatisfied with an idea, they will then search out new intelligible, plausible, and fruitful constructs which will balance their general conceptual model. However, there are both theoretical and empirical reasons to believe that academic learning is not cold and isolated. For example, there is empirical evidence that more affectively charged motivational beliefs, such as students' self-efficacy beliefs, and their goals for learning can influence their cognitive engagement in an academic task. Accordingly, individual students' motivational beliefs may influence the process of conceptual change (These theories are drawn from a general field of motivation which I will present below) (172).

Now the L2 learner is faced with numerous factors and needs in order to display an increase in motivation. Pintrich lists four categories inside the classroom that will affect motivation: Goal orientation beliefs, interest, self-efficacy, and control. Goal orientation will be discussed first.

Pintrich mentions goals as an issue, but specifically mastery versus performance goals. A student with a mastery goal sees intellectual ability as a means to an end, or instrumental for obtaining intrinsically oriented aspirations including the satisfaction of curiosity, self-improvement, and a refined comprehension of people and events (Wigfield, 2002, p. 35). Performance goals on the other hand consist of objectives related to demonstrating competence to the student's self or others (Radosevich, 2007, p. 175).

Pintrich cites multiple research studies in suggesting that when students are expected to process conceptual material in-depth, those who have a mastery/learning orientation increase the probability of conceptual change using Posner's four conditions (dissatisfaction, intelligible, plausible, fruitful), (Pintrich, 1993, p. 177). In a controversially charged Spanish classroom, the teacher must state that work will not be graded by ideological belief (which would rid the need for a highly biased performance goal based on a teacher's political preference), but by using a high amount of accuracy, correct grammar, and the fluency to eloquently express a logical and reasoned thesis. The classroom emphasis on mastery goals would allow for students to focus on historical and contemporary people and events (as said above), and also the ability to grade student work on controversial material. (It should be noted that performance goals do have a positive effect on motivation if a performance goal oriented student receives good grade). Pintrich also states that 
"challenging, meaningful, and authentic" tasks that are relevant to life outside of the classroom can facilitate mastery goal orientation (Ibid, 177). Controversial material discussed in the Spanish classroom can easily be seen outside of school, such as one of the most-talked about issues: illegal/legal Mexican immigration and its correlation with the increase of Spanish in the U.S.

Pintrich also addresses a more obvious factor for motivation in the classroom: interest. Pintrich mentions work done by S. Hidi concerning interest: “...both personal interest and situational interest have a "profound effect on cognitive functioning and the facilitation of learning"' (Ibid, 183). Hidi mentions that "personal interest" will influence students' activation and acquisition of knowledge, effort and willingness to persist on a task, and selective attention (Ibid). Some students might just be purely interested in social studies and history because it is enjoyable by itself. Situational interest on the other hand is specifically influenced by classroom factors. Pintrich mentions challenge, choice, novelty, and fantasy as a few of the components in situational interest. It is possible to apply some of these situational interest factors in the controversial Spanish classroom.

- Challenge: It is difficult to articulate one's genuine thoughts in a TL, especially abstract concepts and opinions.

- Choice: Students have the option of choosing whatever political and ideological position they would like, as long as they can articulate their thoughts using the TL in a logical manner.

- Novelty: As I mentioned above, many U.S. students are not exposed to controversial historical and contemporary material concerning Latin American-U.S. foreign policy, especially academic and peer-reviewed information and ideas that point to the complexity between the U.S. and Latin America countries.

-Fantasy: Magical-realism is a popular literary genre created and refined by one of the most famous authors in the world, Gabriel García Márquez, to explain controversial happenings through literature. One such work of Márquez is One Hundred Years of Solitude, in which he fantastically retells the banana massacre of the United Fruit Company (a U.S. corporation) against banana workers that took place in Santa Marta, Colombia in 1928, as well as North American influence in the literary city of Macondo.

Essentially it is important to have classroom material that maintains the above characteristics, otherwise students will not be interested enough to attend to new information.

Another main factor that the conceptual change classroom needs to consider is self-efficacy. Pintrich gives two definitions of self-efficacy in the conceptual change context. The first can be considered as the students' confidence in their own ideas and conceptions: "In this case, higher levels of self-efficacy or confidence in one's own beliefs would be a hindrance to conceptual change" (Ibid, 186). The second definition refers to self-efficacy as students' confidence in their abilities to use cognitive tools necessary to integrate and synthesize "divergent" ideas (Ibid). The main goal of this paper is not to find a method to fully conceptually change a student, and for this reason the focus will be on the second definition of self-efficacy. If students do not have strategies to research, compare, contrast, or comprehend controversial material, then no amount of interest or mastery goal orientation will allow for solid learning: such a lack of know-how will eventually lead to feelings of inadequacy and hopelessness. A major factor that affects the ability to write and discuss a logical argument depends on the student's research. The internet has multiple resources for research, as well as a library, and it is imperative that student's have the capability to use both sources. Another factor to consider is how much of the TL should be integrated into the curriculum. If it is beyond the students' ability to comprehend the teacher's speech as well as controversial material, then little conceptual change or input will occur, thus severely limiting the opportunity to produce output while creating a low level of motivation. Students' level of proficiency should be considered before any controversial conceptual-material is implemented.

Control factors will ultimately affect motivation in the Spanish classroom. Pintrich discusses internal versus external control: internal control focuses on students' beliefs that they are the main drivers of their learning and success, while external control concerns students' perceptions that learning and success will be mainly affected by outside factors such as the teacher's grading difficulty. In Pintrich's own studies he found that internal control beliefs were positively related to college students' use of metacognitive strategies and deeper processing, plus their actual performance on class exams, lab reports, papers, as well as the final grade in the course (Ibid, 189). Ultimately the teacher would have to create an internal-control environment in the controversial conceptual change classroom, especially when emotions can be high in attributing academic troubles to the teacher's choice of material and supposed political preference.

Because of the delicate nature of controversial material, more time needs to be devoted for students to research and formulate comprehensive ideas about issues. Pintrich recognizes project-based learning in science as a way to extend time to students. Project-based learning is designed for students to investigate a significant problem with a specific question that serves to organize and direct activities (Ibid). The science manner of project-based learning can be copied into a controversial conceptual change Spanish classroom. For example, a long term project could be the study of the Zapatista indigenous movement and its conflict with the Mexican government, private U.S. and Mexican companies, and the world market ideology in southern Mexico. At the beginning of the project date, students will be informed that they will act as members of a jury, defense, prosecution, and judge that will deem multiple members of the conflict as either guilty or innocent (similar to the "Putting Columbus on Trial" method that many middle schools have employed). This project-based opportunity would allow students to look at a contemporary event with living people plus the control of "judgment" over deciding the fate of each group. The Zapatista trial would also require extensive use of the TL in order to communicate ideological and lawful reasons for each group's sentence. 


\section{SElective Factors of Motivation to Consider}

Although factors of motivation according to authors of conceptual change were discussed, addressing motivation in a more general sense can construct a functional classroom using controversial conceptual material. Deci and Ryan (1985) define the study of motivation as "the energization and direction of behavior" with energy meaning the feeling of "needs" and direction as "the processes and structures of the organism that give meaning to internal and external stimuli, thereby directing action toward the satisfaction of needs." (3). So, the need for the student is to learn the language while using direction, or his cognitive structure, to interpret inner and outer factors that could lead towards the fulfillment of such desires: behavior is ultimately affected by the intensity of such a need and the external and internal features that affect cognitive processing.

One of the most studied aspects of need and direction is intrinsic versus extrinsic motivation: those who see themselves as the source of their own motivation are intrinsically motivated, while those who engage in an activity because of rewards, punishment, or a desire to please someone are considered extrinsically motivated (Linnenbrink, 2008, p. 450). Students in a Spanish classroom could be in the class because they like learning new languages or want to move to the TL country (intrinsic), while many are in class because of academic requirements (extrinsic). As with a majority of classes in the U.S., many of these students want to avoid a bad grade, which takes the form of a punishment in a multifaceted way and could cause disappointment to another. At this point in time extrinsic qualities in mainstream education are here to stay, but through self-determination theory (SDT), it is possible to nurture an individual's previous extrinsic perceptions towards intrinsic value in the Spanish classroom.

SDT proposes that three needs must be met in order for human beings to achieve intrinsic motivation: competence, autonomy, and relatedness (Urdan, 2007, p. 303). Competence involves feeling effective in one's continuous dealings with the social surroundings and having a sense of opportunity to implement and articulate one's capacities. Autonomy consists of student recognition that behavior or decisions ultimately come from the learner's self, even with outside influence, while relatedness is the individual's feelings of connectedness to others and the community, or in this case, the students and teacher that make up the classroom (Ryan, 2007, p. 7). The use of controversial conceptual material could cause some students to feel inferior because of the competitive nature of debate between peers, plus varying participant language capacity, which could undermine competence. Within the class it is important to foster rules that demand respect for each student's belief and extended time for an individual to express complicated opinions that require even more patience because of the TL. Controversial conceptual education advocates autonomy for students because of its emphasis on the importance of individual opinions, and the only limitation is that beliefs are stated in the TL with logical evidence. Finally, to promote relatedness, a teacher must encourage unity within the class and emphasize that all the students are working together as a team to reach increased Spanish fluency even if there are varying opinions: every student-to-student interaction represents an opportunity for output and intake, and controversial conceptual material only acts as the subject to inspire such conversation.

Students may have an intrinsic interest in Spanish, but if the perception of success or failure in class work and goals are not attributed to the student's own work, there will be a decrease in motivation to engage controversial conceptual material. More importantly, a student has to have a balanced locus of control, which refers to "an individual's generalized expectations concerning where control over subsequent events resides," or in this case, a student's belief about his or her own control concerning the controversial conceptual material aspect of grades and success (Locus of Control). There are numerous factors that could affect a student's locus of control, including internal features such as academic and emotional ability, previous experience, habits, attitudes, self-perceptions, maturity, attention and mood during task, while external characteristics that include instruction, family, other students and directions can alter the locus of self control (Weiner, 1980, p. 42). I believe that controversial conceptual material gives students a majority of the control because they are encouraged to agree, disagree or some combination of the two within a controversial subject, as long as they are able to voice their logic in the TL. The teacher acts as an initial source of information and direction, since the topics included in the curriculum are largely unknown to a majority of U.S. students. Afterwards, students are encouraged to form their own opinions and defense, while the teacher steps back as a facilitator during student dialog and activities. This form of instruction can encourage a student's perception of success or failure in the classroom as internal, or based on his own effort and ability, versus an external sense of control which is based on factors outside of a student's management.

There are more than perceived internal and external factors that can affect the locus of control according to attribution theory. In addition, a student might ask if the cause of success or failure is stable or unstable, and if that factor is controllable or uncontrollable (Vockell, n.d.). For example, if a well performing student enters into a test after hearing that her uncle died, and then sees that she performed poorly on the exam, she would attribute her failure to an external, unstable and uncontrollable cause that affected her internal ability to perform successfully. According to Weiner, one of the forefathers of attribution theory, (1980), the individual will attempt to explain their successes and failures based on personal ability, exerted effort, difficulty of the task, and luck (41). Students will most likely pursue academic endeavors within the controversial conceptual classroom if success and failure are ascribed to internal, unstable factors over which they have control (also known as effort) (Vockell, n.d.). It is important that the controversial conceptual classroom make effort a key factor in student perceptions of success and failure: if students fail, 
they only have themselves to blame. If LLs succeed, then they can attribute their success to their own personal effort and ability.

In order for students to have a balanced locus of control, the teacher has to provide an atmosphere that offers the possibility of success for everyone. The level of perceived difficulty in reaching success, though, can be varied individually amongst students. Addressing students' beliefs about their own capability to perform well is known as selfefficacy. According to Albert Bandura, one of the most renowned experts about self-efficacy, an individual that lacks a feeling of capability, even if they have the capacity, will experience little incentive to perform a task:

"...human motivation..[is] based more on what an individual believes than on what is objectively true. Unless people believe that their actions can produce the outcomes they desire, they have little incentive to act or to persevere in the face of obstacles. For this reason, how people behave can often be better predicted by the beliefs they hold about their capabilities than by what they are actually capable of accomplishing...(Schunk, 2007, 86).

A balanced locus of control and intrinsic motivation will be hard to spot if a student feels that he is incapable of reaching some kind of success in a given task. An individual develops self-efficacy based off four personal interpretations of internal and external factors: interpreting one's own performance, interpreting the performance of others, interpreting others' expressions of your capabilities, and interpreting one's psychological state (Mayer, 2007, p. 505). In the classroom, a student would interpret his performance by reflecting on previous experience and the current situation. He would also analyze his peers' performance, because if a majority of the class can do it, why can't he, and if they can't, maybe he is unable to as well. Others' expressions directed toward the student, including peers and the teacher, influence perceived self-efficacy; if they are portraying genuine smiles and encouraging words, a student is more likely to have a higher level of self-efficacy, while worried looks and cautionary words could decrease the student's perception of capability. Lastly, the student's reflection of his psychological state has an impact. If he feels relaxed and thoughtful after examining an assignment or test instruction (assuming the end result is important to him), the student has a higher sense of self-efficacy. If the student recognizes that he feels nervous, unconfident, and feels his heart beat faster, then his perceived notion of self-efficacy will be lower and may inhibit his ability to perform well.

The above factors influence self-efficacy, and these beliefs ultimately affect student work by revealing how much effort the learners will spend on a task, how long they will persevere when approaching difficulties, and how resilient they will be in the face of "adverse situations" (Parajes, n.d.). A teacher is unable to control for all four factors that form self-efficacy other than providing material that is appropriate for the LL, which would then allow students to see their peers succeed and give them a sense of "I can too!" Additionally, a teacher's observable reactions to student answers or work should be managed appropriately for each individual LL. For example, if there is a shy Spanish student with lower self-efficacy, the teacher should express positive commentary in a non-patronizing manner, as this has the potential to increase the student's perception of capability. On the other hand, a student with too much perceived sense of selfefficacy who is not performing well should receive negative but constructive feedback.

The considerations of intrinsic motivation, locus of control, and self-efficacy are important for controversial conceptual activities because of its focus on a communicative language teaching (CLT) approach. Human beings are a species of constant communication, and honing this quality in a class activity can arouse genuine exchange of ideas which has the potential for intrinsic interest. But in order for productive output and intake to take place, the individual must feel that he has the capacity and control to contribute to a conversation. If limits such as strict grading on correct verb conjugation, pronunciation, and teacher interruptions occur, the student might feel that he does not have the selfefficacy to express ideas or the control over a genuine conversation, which is what is required to execute controversial conceptual material. The teacher needs to set grading standards that are not based on how many errors or mistakes the student has, but on the amount of observable effort that is exerted. Most importantly, the teacher has to verbally convey this idea to students since individual perceptions of success and control are not based on what is objectively true, but on what is believed and interpreted by the LL. People control success by reducing the chance of failure, and if the chance of failure is small in comparison to success, students might be more likely to engage in the activity. The teacher should convey to students that making mistakes and errors are important, if not integral, to learning Spanish, and the only failure is not taking the chance to make the mistake.

\section{CONTRoversial CONCEPTUAL MATERIAL in ACTFL STANDARDS}

One could ask how controversial conceptual material fits into a collectively acceptable way of teaching students. It is worth examining the method in each standard of ACTFL's philosophy on language learning (ACTFL, n.d.). There are five categories that include communication, cultures, connections, comparisons, and communities.

COMMUNICATION

Communicate in Languages Other Than English

- Standard 1.1: Students engage in conversations, provide and obtain information, express feelings and emotions, and exchange opinions.

Controversial conceptual material requires students to research and ultimately express their opinions in the form of debate or conversations.

- Standard 1.2: Students understand and interpret written and spoken language on a variety of topics. 
Focusing just on controversial conceptual material would be overbearing if it was the only topic studied, but in today's teaching context, it offers a new topics for language learning.

- Standard 1.3: Students present information, concepts, and ideas to an audience of listeners or readers on a variety of topics.

The idea of putting the Zapatistas, world market ideology, and other actors on trial would allow students to present documents, pictures, literature, music, and other mediums to the class.

CULTURES

Gain Knowledge and Understanding of Other Cultures

- Standard 2.1: Students demonstrate an understanding of the relationship between the practices and perspectives of the culture studied.

Controversial conceptual material is based on presenting the TL life and perspectives that is not addressed in many classrooms.

- Standard 2.2: Students demonstrate an understanding of the relationship between the products and perspectives of the culture studied.

Products such as agriculture and manufactured goods are not only a main source of imports into the U.S. but also a point of contention between social groups, economic leadership, and the TL population as a whole; the goal of controversial conceptual material is for students to be acquainted with these perspectives through Spanish learning.

CONNECTIONS

\section{Connect with Other Disciplines and Acquire Information}

- Standard 3.1: Students reinforce and further their knowledge of other disciplines through the foreign language

Art, music, literature, news, journalism, and other fields are mediums that social and individual TL voices have used to express themselves through conflicted history and contemporary issues, and are key components of controversial conceptual material.

- Standard 3.2: Students acquire information and recognize the distinctive viewpoints that are only available through the foreign language and its cultures.

Many U.S. students are not aware of forced political disappearances, which were more prevalent in the Southern Cone of South America during the dirty wars of the 70's and 80s. Concepts like "desaparecer" provide an insight into viewpoints that were formed out of a collective sentiment of fear and oppression.

COMPARISONS

Develop Insight into the Nature of Language and Culture

- Standard 4.1: Students demonstrate understanding of the nature of language through comparisons of the language studied and their own.

Controversial conceptual material draws on students' previous conceptions of the world, which have been formed in English, and relies on TL learning to either accommodate or assimilate new material, thus allowing the learner to alternate between language intake and production.

- Standard 4.2: Students demonstrate understanding of the concept of culture through comparisons of the cultures studied and their own.

Controversial conceptual material seeks to expose language learners to alternative life styles not seen in the U.S. For example, subsistence farming and the culture that revolves around the small scale and community based Latin American activity versus large scale agricultural production with John Deere equipment.

\section{COMMUNITIES}

Participate in Multilingual Communities at Home \& Around the World

- Standard 5.1: Students use the language both within and beyond the school setting.

Spanish is a widely used language in the United States, and with the right pretense, there are multiple venues for discussing controversial issues, such as Latino social clubs, restaurants, visiting speakers and blogs.

- Standard 5.2: Students show evidence of becoming life-long learners by using the language for personal enjoyment and enrichment.

There is a strong doubt that any method or approach will guarantee students' motivation to be life-long learners, but controversial conceptual material can present TL learners with alternative domestic opportunities that stem from hot issues, such as disadvantaged Latino community in the Boys and Girls Club and social advocacy groups. The method can also expose students to further foreign prospects of volunteering or doing an internship.

\section{CONCLUSIONS}

Goal orientation, interest, self-efficacy, and control factors are only small parts to a larger puzzle of motivation inside the Spanish classroom. In fact, everything mentioned in this paper is only a basic start to how a Spanish classroom in the U.S. will need to increase motivation using controversial conceptual material. Inevitably the ideas proposed here are contingent on the personality of the educator, students' temperament, scholastic resources, and a thousand other variables. However, the above authors' contributions form a base for a potentially successful increase in L2 learners' motivation by introducing controversial conceptual material. The mere presentation of controversial conceptual material 
is novel and bound to catch students' interest compared to many educators' beliefs that adolescent L2 learners are "in their own world" and thus cater to an over generalized idea of cognitive immaturity. If a well delivered curriculum in conjunction with the listed psychological and second language theory is applied, today's students may have a higher propensity to be motivated by previous unknown and conflicting realities and relationships between their country and the TL nation.

\section{REFERENCES}

[1] ACTFL. (n.d.). National Standards for Foreign Language Education - American Council on the Teaching of Foreign Languages. Home - American Council on the Teaching of Foreign Languages. Retrieved March 5, 2010, from http://www.actfl.org/i4a/pages/index.cfm?pageid=3392

[2] ACTFL. (2000). Standards for Foreign Language Learning. Preparing for the 21st Century. Retrieved March 5, 2010, from www.actfl.org/files/public/StandardsforFLLexecsumm_rev.pdf

[3] Atherton, J. (2005). Assimilation and Accommodation. Learning and Teaching Home. Retrieved December 6, 2008, from http://www.learningandteaching.info/learning/assimacc.htm

[4] Boeree, G. (n.d.). Jean Piaget. Personality Theories. Retrieved October 30, 2008, from

[5] Cummins, J. (n.d.). BICS and CALP. BICS and CALP. Retrieved March 5, 2010, from faculty.tamucommerce.edu/jthompson/resources/BICS\%20and\%20CALP.doc

[6] FEDEFAM - English version. (n.d.). Desaparecidos. Retrieved December 6, 2008, from http://www.desaparecidos.org/fedefam/eng.html

[7] Kroft, S. (2008). The Price Of Bananas, Steve Kroft On How Colombian Paramilitaries Landed A U.S. Corporation In Hot Water. CBS News - Breaking News Headlines: Business, Entertainment \& World News . Retrieved December 6, 2008, from http://www.cbsnews.com/stories/2008/05/08/60minutes/main4080920.shtml

[8] Lightbown, P., \& Spada, N. (2006). How Languages Are Learned (Oxford Handbooks for Language Teachers S.). New York: Oxford University Press, USA.

[9] Linnenbrink-Garcia, L., \& Fredricks, J. A. (2008). Developmental Perspectives on Achievement Motivation. Handbook of Motivation Science (1 ed., p. 450). New York: The Guilford Press.

[10] Locus of control - WikEd. (2005). WikEd. Retrieved April 13, 2010, from http://wik.ed.uiuc.edu/index.php/Locus_of_control

[11] MacIntyre, P. (n.d.). Individual Differences and Instructed Language Learning. Anxiety and Emotion in Second Language Acquisition. Retrieved November 14, 2008, from faculty.uccb.ns.ca/pmacintyre/research_pages/journals/motivation_chapter_2002.pdf

[12] Mayer, R. E. (2007). Learning and Instruction (2nd Edition) (2 ed.). Alexandria, VA: Prentice Hall.

[13] Pajares, F. (n.d.). Self-efficacy Lecture - Pajares. Self-Efficacy Beliefs in Academic Contexts: An Outline. Retrieved April 13, 2010, from http://www.des.emory.edu/mfp/efftalk.html

[14] Pintrich, P., Marx, R., \& Boyle, R. (1993). Beyond Cold Conceptual Change: The Role of Motivational Beliefs and Classroom Contextual Factors in the Process of Conceptual Change. Review of Educational Research, 63(2), 167-199.

[15] Posner, G., Strike, K., Hewson, P., \& Gertzog, W. (1982). Accommodation of a scientific conception: Toward a theory of conceptual change. Science Education, 66, 211-227.

[16] Radosevich, D. J., Allyn, M. R., \& Yun, S. (2007). Predictive Validity of Goal Orientation: Four-Factor versus Three-Factor Model. Review of Business Research, 7(4), 175.

[17] Ryan, R. M., \& Deci, E. L. (2007). Overview of Self-Determination Theory: An Organismic Dialectical Perspective. The Handbook of Self-Determination Research (1 ed., p. 7). Rochester: University of Rochester Press.

[18] Schunk, D. H., \& Pajares, F. (2007). Competence Perceptions and Academic Functioning. Handbook of Competence and Motivation (1 ed., p. 86). New York: The Guilford Press.

[19] The Disappeared. (n.d.). The North Dakota Museum of Art. Retrieved December 6, 2008, from http://www.ndmoa.com/pastex/disappeared/index.html

[20] Urdan, T., \& Turner, J. C. (2007). Competence Motivation in the Classroom. Handbook of Competence and Motivation (1 ed., p. 303). New York: The Guilford Press.

[21] Vockell, E. (n.d.). Attribution Theory and Motivation. Attribution Theory. Retrieved April 13, 2010, from http://education.calumet.purdue.edu/vockell/EdpsyBook/Edpsy5/edpsy5_attribution.htm

[22] Weiner, B. (1980). A Theory of Motivation for some Classroom Experiences. Perspectives on Attribution Research and Theory (p. 41). Cambridge: Ballinger Publishing Company.

[23] Wigfield, A., \& Eccles, J. (2002). Development of Achievement Motivation (Educational Psychology). Toronto: Academic Press.

Antonio R. Iaccarino is a native of Davenport, Iowa, USA. He graduated from Marlboro College, Marlboro, Vermont, in 2010 with a degree in psychology/Spanish and a focus on applied linguistics. In addition Iaccarino's research interests include racial, economic, political, and societal issues in the country of Colombia.

Iaccarino has taught EFL in Colombia and Spain, ESL in the United States, and continues to be a freelance educator and writer. Selected articles include: "Muslims in Medellín: Identity on the Margin" and "Cost of cocaine paid in full with Colombian lives." 